\title{
CULTURE AND DEVELOPMENT ETHICS
}

\section{Needs, women's rights, and Western theories}

\begin{abstract}
Des Gasper $^{1}$
A prefinal version of a paper which appeared in 1996 in Development and Change, 27(4), pp. 627-61, and was later reprinted in: Amartya Sen: Critical Assessments of Contemporary Economists, edited by J.C. Wood \& R.D. Wood, 2007, London: Routledge, vol. 3, pp. 3-36.
\end{abstract}

\begin{abstract}
Can development ethics avoid presuming that European cultures have universal validity and yet also avoid treating every distinct culture as sacrosanct and beyond criticism? While work on "culture and development" valuably stresses the importance of cultural difference and identity it has often been hindered by conceptual limitations when faced with the ambiguities, variety, conflict and change within societies. This paper queries a communitarian belief that morality cannot be anything other than whatever a community's norms are; and suggests that recent development ethics work usefully blends universalist ethics with room for local traditions and choices. As advances on both (a) forms of liberalism that are universalist in scope but Eurocentric and over-individualistic in content, and (b) relativist forms of communitarian or post-modern ethics, three current approaches are noted: (c) new work on Basic Human Needs theory, including Amartya Sen's capabilities approach; (d) Martha Nussbaum's Aristotelian extension of Sen; and (e) Onora O'Neill's Kantian development ethic. Particular attention is given to disputes concerning women's rights.
\end{abstract}

\footnotetext{
${ }^{1}$ Acknowledgements: This is a substantial revision of an invited paper prepared for meetings organized by the National UNESCO Commission in the Netherlands (Amersfoort, May 1993; Woudschoten, June 1994), which appeared as ISS Working Paper 195 (April 1995) and in the Woudschoten meeting proceedings. I am grateful for reactions and suggestions from John Cameron, Raff Carmen, Nigel Dower, Shanti George, Mark Lutz, Onora O'Neill, Purna Sen, Thierry Verhelst, Raymond Apthorpe, Jan Nederveen Pieterse, C.A.O. van Nieuwenhuijze, Peter Waterman, and especially Sipko de Boer and Andras Krahl. The present version has benefited from comments by an anonymous referee which led to extensive reworking. Responsibility for the opinions expressed remains with the author.
}

Key: $\mathrm{BHN}=$ Basic Human Needs; BMN = Basic Material Needs; C\&D = Culture and development; DE = Development ethics. 


\section{Introduction}

Unfavourable comparisons are made between the levels of life-expectancy, literacy and related matters in certain countries, such as India, and levels in other countries such as Sri Lanka and China which have had similar average income but achieved far more. Or is use of the term "achieved" a reprehensible and Eurocentric-cum-developmentalist imposition of a unitary concept of improvement, blind to diverse and non-comparable ways of human existence ? This reaction is suggested by, for example, the recent "Development Dictionary" edited by Wolfgang Sachs (1992). Perhaps some people prefer short, literacy-free lives ?

Also available now are sex-disaggregated comparisons which reveal that the achievement-shortfall applies primarily to women. For example, in South Asia, women's lives on average are shorter (or no longer) than men's, in contrast to in the rest of the world. In Pakistan in the 1980s, female literacy was half the figure for men, compared to almost parity in Tanzania, and maternal mortality was fifty per cent higher than Tanzania's, even though Pakistan's real per capita income was four times greater (UNDP, 1990). But perhaps the women in the two countries, in their diversity of culture and identity, are equally content ? - so the "Development Dictionary" might suggest. If they were equally content, would that be sufficient justification for their different conditions?

Development ethics must consider such claims and questions of cultural plurality and divergence. In this paper I try to characterize the work calling itself development ethics, the challenges it faces on the grounds of cultural difference, and some varied recent responses which combine a universal ethical discourse with cultural relativity.

Section 1 will sketch work in development ethics, in terms of a historical and ongoing relationship between three necessary stages: first-stage ethical reactions to experience, second-stage formal theorization, and third-stage adjustment to practice in a reality more complex than any theory. It notes the growing focus on whether one can avoid presuming one's own culture has universal validity and yet also avoid treating each culture as sacrosanct and beyond criticism. Can we establish some well-grounded prioritizations that recognize both cultural variety and shared humanity?

Section 2 looks at the stream of "culture and development" work, which valuably stresses, in various ways, the importance of cultural difference and identity; but at the same time raises ethical questions which it often fails to handle adequately. We will query a communitarian belief that morality cannot be anything other than whatever a community's norms are: that there is no other basis for evaluation.

Recent development ethics work goes some way to integrating the discussions of ethics and culture and balancing universalist ethics with room for local tradition and local choice. As alternatives to both (a) forms of liberalism that are universalist in scope but Euro-centric and over-individualistic in content, and (b) relativist forms of communitarian or post-modern ethics, three current approaches will be noted: (c) new work on Basic Human Needs theory, including Amartya Sen's; (d) Martha Nussbaum's Aristotelian extension of Sen; and (e) Onora O'Neill's Kantian development ethic. 
Section 3 suggests that basic needs ethics offer an area for consensus, a pattern of justification for common minimum requirements, within which details can vary according to situation and culture. The more extensive however that needs ethics become, the more they may satisfy and inspire some, through use of a complex picture of human personality and well-being, but the more they can lose the assent of other audiences. Section 4 looks at this danger in Nussbaum's work, and at her recent volume on 'Women, Culture, and Development'; and considers, again with special reference to women's rights, O'Neill's contrasting treatment of the meaning of justice in a multi-cultural context and of criteria for acceptable cultural variation. Section 5 sums up.

\section{Three stages in development ethics: emerging cultural questions}

Goulet's early definition of development ethics (DE) -- as concerning the `ethical and value questions posed by development theory, planning and practice' (1977:5) -- remains valid; what it will cover depends on how broadly we interpret 'development'. Dower presents development ethics as a branch of philosophical applied ethics which treats issues that arise in partly-controllable social change, at whatever social level, and whether in economically rich or poor countries or in their mutual relations (e.g. Dower, 1992). He makes a case for thinking of it as a single field, which will parallel traditional ethics' question "How ought one to live as an individual?", by asking in addition "How ought a society to exist and move into the future?" (p.14). Elsewhere he and others add a similar question for world society. My own characterization of development ethics focused more on issues in low-income countries and in their relations to the rich (Gasper, 1994); I expect in practice some divisions of Dower's field into sub-fields that attract different audiences.

I will sketch three stages of work in DE, taken in the narrower sense; but much of the discussion applies for Dower's broader field too. We will see how (inter-) cultural issues have emerged openly as challenges that must be faced.

Crocker's survey in "World Development" (1991) proposes that "development ethics" as a self-conscious and cumulative body of work was founded by Goulet, insofar as by any one person. Goulet's "The Cruel Choice" (1971) is part of a first stage in DE work, which reacts to and reflects on problems and horrors of development and of non-development, capitalist or socialist, and puts forward views of human interests, rights, duties, and dilemmas. Peter Berger's "Pyramids of Sacrifice" (1974) was another influential early exemplar. First-stage work has reconsidered meanings of "development" and advocated or examined concepts like "equity", "basic needs", "participation", "autonomy", and "empowerment".

Utilitarian economics, whether in neo-classical, Fabian or Leninist variants, has heavily shaped the concepts and policies of development (see e.g. Gasper, 1993). Much first-stage DE work reacts against economistic views of development and the implicit, culturally impoverished ("economic man") sets of values. ${ }^{\mathrm{i}}$ Goulet emphasized that people seek compatibility and synergy between their significative values (meanings) and their performative values (activity-choices); but that a gap has opened, notably in developing 
countries, between inherited significative values and the new performative values demanded in economic development. This may undermine both sets of values, whereas: "Every society must feel that its values are worthy of respect if it is to embark on an uncertain future with confidence in its own ability" to handle that future (Goulet, 1971:49). Many policies are to protect a vulnerable identity or to make it less vulnerable. Goulet argued that while this cultural core demands protection, there can be great flexibility in more peripheral components of a culture.

First-stage work has had some real but limited impact. Advocates of a poverty-focus and popular rights did contribute to modifications of adjustment programmes in the 1980s -- though no doubt more was due to civil disturbances and political instability than to intellectual conversion of policy-makers. The official doctrine of the Dutch aid programme now includes much first-stage discourse. Its 1990s flagship policy statement, the book "A World of Difference", has major emphases on each of culture, democracy, individual freedom/ autonomy, basic needs, and a range of other posited human rights. But it makes only brief reference to the possible conflicts amongst this set of considerations $(1991: 196,204){ }^{\text {ii }}$ To deepen criticism and to clarify and face conflicts of principles, we require more coherent philosophical alternative(s) to economic growthmanship.

So first-stage development ethics's criticisms of economism and reference to multiple different appealing principles are not enough. "Second stage" theorizing tries to refine and relate different principles and build systematic theoretical alternatives. That too is not enough: life's richness outstrips any single system. We require a "third stage", which takes abstracted theoretical systems back to the real worlds of practice and compromise. Each stage has a permanent role: first-stage reaction to new issues and experience; second-stage systematization and deepening of those responses; and third-stage application and adaptation of the systems when facing real choices. The stages represent more an intellectual than a historical sequence, since each will always be necessary; there is some chronological association though, as the proportion of second and then of third stage work grows over time. ${ }^{\text {iii }}$

The second stage of DE involves attempted theoretical justification of first-stage positions, by probing foundational issues of the nature of well-being and of criteria for what is good/right, including the claims of different philosophical traditions, and the methodology of ethical theorizing and practice. ${ }^{\text {iv }}$ Three important examples of foundational probing are Amartya Sen's capabilities theory (Sen, 1985; Nussbaum \& Sen, eds. 1993; Nussbaum \& Glover, eds. 1995), Onora O'Neill's modified Kantian ethic (1986), and attempts to extend John Rawls's theory to world level (e.g. Beitz, 1979).

Neo-Kantianism, for example, can conceptualize development as extending individuals' ability to set and pursue ends freely chosen by themselves. It implies rights to an equal voice, literacy, information, participation and public accountability (Cameron, 1992). As formulated (though not theorized) in "A World of Difference": "Is autonomy not the goal? Autonomy for individual people in a society, so that they have the opportunity from the outset to decide for themselves what development should mean, what life and existence should signify?" (BuZa, 1991:38; my emphasis). ${ }^{\mathrm{v}}$ The document later advocates "a development ideology which is based on the principle of autonomy" for individual women (p.205). 
But what are the identities of these "individuals"? And what precisely can one mean by free choice in a world of many determining factors? We may need a richer, more social, picture of the living, choosing, individual than in (neo-) Kantian and Rawlsian models. Neo-Aristotelianism offers one such basis, exemplified in Martha Nussbaum's deepening of parts of Sen's work. Indeed its claims arguably become too extensive, too rich. We touch on this in Section 4.

Such theory building is relatively slow and abstracted. It leaves things out, especially at first; starts with models from disciplines that are strong on formal theorizing, notably philosophy and economics; and risks losing touch with the variety and root discontents from the first stage. The research programme of Sen, Nussbaum, Crocker and others moves ahead promisingly in its own terms (see e.g. Crocker, 1992, 1995; Nussbaum \& Sen, eds., 1993), and may well communicate to and influence some mainstream economists and governments, for example via the UNDP Human Development Reports. However, work that is not by philosophers or economists tends to reflect a wider range of experience and factors and may reward the general reader more (see the mini-survey in Gasper, 1994).

At present a range of writers are strengthening critiques of pure market liberalism and of commodity-centering of life. Many adopt a "Basic Human Needs" position (see e.g. Aman ed., 1991; Doyal \& Gough, 1991; Ekins \& Max-Neef eds., 1992). At the same time attacks on "needs" discourse claim that it treats people like animals, by neglecting their quintessentially human activity of cultural construction of identities, meanings, values, and societies; and that it is paternalist and degenerative in practice (see e.g. Illich, 1992). Others declare that "development ethics" as a whole is Northern / Western thought parading as universal, mystifying abstract ethical categories inherited from long past, while neglecting the specificity, richness and variety of cultures. Similar points figure in attacks on the notion of "development" itself.

The "Development Dictionary" (ed. Sachs, 1992) provides a strong version. Sachs and his fellow authors refer to "development" as the global project tabled in President Truman's 1949 inauguration speech. They present the speech as epoch-making because it took over the longstanding Westernization project minus the negative connotations of colonialism; "development's hidden agenda was nothing less than the Westernization of the world" (Sachs, pp.3-4). Their attacks on subsequent mainstream practice hit many targets, but try to flatten everything in sight: "development does not work" (p.1) seems an insufficient account of East Asia's third of humanity or the near-doubling of life expectancy in much of the South. Illich's claim that "most people become poorer as GNP grows" (p.93) is untrue according to available measures but perhaps reflects a definition of poverty based instead on some pre-existing cultural norms. Indeed Sachs claims that the South is now devastated by "vast furrows of cultural monoculture" (p.4).

"Development" is also attacked on grounds that it proffers a universal concept of social improvement. Normative usage of the term is allegedly incompatible with the reality of "diverse and non-comparable ways of human existence" (Sachs, 1992:3). Thus Esteva considers endogenous development a contradiction in terms, for "endogenous" implies coming out of a specific culture and its values, whereas "development" implies some single measure of improvement -- rather than diverse culture-specific measures -- and "the oneness, homogeneity, and linear evolution of the world" (1992:12). In fact comparability does not 
presume simple homogeneity. Japanese culture and values are different from American, yet some comparison of their degrees of "development", each measured partly in terms of their own values, is possible, and done (e.g. in national income measures, governmental and alternative). Further, Esteva and his colleagues themselves go on to make greater comparisons, of the value of different ways of life. They do not merely say that, e.g., American values and $\mathrm{X}$-ian values differ, or that $\mathrm{X}$-ians appear more developed in terms of their own values than Americans are in terms of theirs; they go further and criticize American values.

Like Corbridge (1994), I accept parts of the post-modernist analysis of "development", but query attempts -- post-modernist, communitarian, or New Right -- to restrict the scope of morality to national or local communities. ${ }^{\mathrm{vi}}$ Apel notes what is at stake: when the post-modernist "critique of rationality calls into question [by reason!] the fundamental identity and unity of reason, in the name of difference and plurality, it overshoots the mark and threatens the very diversity that it aims to protect" (Apel, 1992:16; my interpolation). For the strong can then declare themselves "different" and entitled to pursue their own rationality and the unique values of their own allegedly incomparable way of life, including by consuming the weak -- as in apartheid South Africa.

In Martha Nussbaum's terms, the adoption of a relativist stance by outside observers, as currently in vogue, is the involvement of the tourist: the detached amused observer who is not forced to seriously ask herself what it means to live by a certain norm (1992:240). The stance serves the convenience of rich Northerners and Southern elite-members who both wish no claims against their life-styles. To some significant extent, we can abstract from local specifics and morally reflect in a detached way. This is the thrust of for example the Kantian and needs ethics which we look at later. Further, what does globalization tend to leave in the past: universalizing categories or self-contained social and moral islands? Surely the latter more than the former. Yet we must also query forms of ethical universalism which ignore different local conditions or leave no space for distinctive world-views, traditions and interpretations.

Current work in DE includes deeper attention to categories like "needs" and "development", and to the 'third stage' demands of practice: how to achieve more influence in a world of rampant capitalism and other furies, including through possible alliances among different ethical views. While DE has indeed typically relied on "Western" categories that claim universal application, like needs, utility, rights, and liberties, this Western philosophy is not purely the reflection or root of Western mainstream economic life: it is often critical of that life (and thus frequently ignored). Its universalistic principles contain strong democratic potentials (Hussein, 1992).

In considering the ethical challenges of cultural diversity, let us now examine what the work on "culture and development" can offer. It directly raises many ethical questions but its own handling of them has largely remained at the first stage. Recent work in development ethics, discussed in Sections 3 and 4 , tries to go deeper. 


\section{2. "Culture and development": meanings and ethical questions}

This section offers a development ethics based critique of selected 'culture and development' literature. I will draw out different meanings of 'development' and 'culture', including a lead meaning of culture as a distinctive ensemble of values and perceptions; clarify the values attached to 'culture' itself in different conceptions of 'development'; and stress the incomplete definition and integration of groups by such ensembles of views, and the unclarity, heterogeneity and fluidity of views within groups. Later we will add arguments that the moral weight of a consensus in views, when found, will still depend on the conditions which generate it.

Culture as barrier, instrument, or ethical foundation?

At least three types of meaning of "development" deserve attention here: 1. qualitative change (in society/economy/polity /...); 2. intervention or policy; and 3. improvement. In the "culture and development" (C\&D) literature different "cultural" and/or ethical issues arise for each. The following table mentions some foci of attention.

\section{"DEVELOPMENT"}

Positive meanings

3. Improvement

meaning

\section{"CULTURAL" ISSUES ARISING}

1. Culture as: a) engine or brake?;

b) independent or dependent variable?...

2. a) Local culture as target/instrument

b) Culture of the interveners

c) Inter-cultural relations

3. What criteria of improvement?

- Economistic, or wider?

- Immanent or trans-cultural?

Much attention goes to the positive issues in area 1 on qualitative change (e.g., is a particular culture a brake on commercialization?) and their policy versions in area 2 a (e.g., how can a brake be eased by some cultural engineering?). Corresponding views include the following.

(A1) One mainstream view takes culture as a fully accomodating dependent variable which does not influence (economic) development, and "so" can be ignored. This is the stance of many economists.

(A2) An opposite mainstream view sees culture instead as often an obstacle to economic development; again the concern with culture is instrumental.

(A3) A third (and overlapping) type of mainstream instrumental stance takes culture as a policy tool, to be studied and made use of. This stance arises from an understanding that failures to take into account distinctive local culture, motives and meanings contribute to policy- and project-failures (Kottak, 1991).

(B) The claim that local culture is an essential means or modality, so that if it is not respected then nothing will succeed, represents a stronger version of (A3). It implies many "road[s] to development" (BuZa, 
1991:237); but the development goal itself can here still be viewed as universal in content.

(C) The view that people have basic cultural needs. Typically an inherited societal/group culture is seen as the major vehicle for fulfilment of the needs. (This can link to views D1, D2, D3 below.)

For this paper the other areas in the table (2b, $2 c$ and 3$)$ are more important, especially inter-cultural relations and criteria of improvement, which lead directly into development ethics. Here are some of the value stances on "culture" found in work in those areas.

(D1) A separable independent concern: culture is accorded independent value, making it "an important part" of development.

(D2) A constitutive independent concern: fulfilment of cultural needs is not only independently valued, but occurs through all the media of social activity not just through a separate "part".

(D3) An overriding independent concern: inherited culture is of incomparable and absolute value, and must be preserved.

(E) A liberal stance: since local culture is felt by many people to have independent value, it should be respected, though as just one criterion, not an overriding one.

(F) A foundational concern: each culture is the source of criteria that define "the good life" or "development" for its members. Here there are various "paths of development", with their own goals. Verhelst, for example -- in his well-known "No Life Without Roots - Culture and Development" (1990) -- argues that alternative forms of modernity are possible, and exist, besides Westernization; and fortunately so, given Western civilizational crises. Advocates of "endogenous development" take this position $(\mathrm{F})$, and/or (B).

(G) Culture as oracle: one should refer to "the prevailing culture" for the answers on what objectives and criteria to adopt. This can be a strong version of (F), and a claim that one must only measure development in terms of the given culture's values.

(H) " "Culture" not "development"': the claim that the values propounded within "development" are culturally unacceptable (e.g. because deemed individualistic and materialistic) and deserve rejection.

We could add other possibilities, and mixed positions. But the key point here is that ethical claims arise in each of positions (D) through $(\mathrm{H}){ }^{\mathrm{vii}}$

What does "culture" mean in the above positions ? Van Nieuwenhuijze warned that: "The current interest in culture and development is largely a Western response, under a typically Western label, to Third World events not necessarily announced there as cultural" (1983:18). As with "development", a minimum of three meanings of "culture" recur in the C\&D work: culture as a residual category; culture as everything; and culture as values and attitudes. (The interested reader can match them to the positions given above; in certain cases more than one applies.)

Sometimes "culture" implicitly concerns a residual, whatever is marginal to economistic thought. ${ }^{\text {viii }}$ Behind the code-word stands a set of concerns rather than one thing (van Nieuwenhuijze, 1983; Kloos, 1985): a huge, disparate, and hard-to-handle collection, including local knowledge, local values, local concepts and perceptions of life and the world, local institutions, "non-economic" values; needs and styles of 
expression, activity, meaning, identity, dignity and beauty; and more. While the background concerns are important, to make useful statements concerning this conglomerate becomes very difficult.

In a second variant in $\mathrm{C} \& \mathrm{D}$ literature, "culture" becomes everything: "By culture, therefore, is meant every aspect of life" (Verhelst, 1990:17); "Culture may be regarded as whatever characterises a community" (BuZa, 1991:190). It gets "left out" so often because "it" is too big to "include" -- the set of all values, norms, attitudes, habits, ways of doing, artefacts, and institutions. Authors probably mean both more and less than this: we are looking (also) for underlying or associated patterns of values, habits, etc.; for generative factors, not just a heap of aspects.

So if we try to become more specific, culture contains at least "values and attitudes", ways of thinking and feeling: a third standard C\&D formulation. Variants here include "mentalities" (BuZa, 1991:190) and Hofstede's definition: the shared mental programming which distinguishes one group from another. Hofstede explicitly places values as culture's core (1994:8). This third formulation is the most relevant here. We are interested in: inter-cultural relations when such sets of values conflict; and intra-culturally, how far are cultures in fact unified, and who benefits from particular codes and rules?

\section{When in Rome, do as the (ancient) Romans?}

We would have less need to study culture if there was only one, as sometimes assumed in economics. In reality we face plurality, dissensus and ethical issues of inter-cultural relations. The more one emphasizes the distinctiveness, persistence, centrality and value of a societal culture, the larger become the questions about inter-cultural relations. At world level some see a series of yawning gulfs, widening as parts of "the" Third World rethink direction. Each major culture area is indeed different, allegedly even "a universe unto itself - neither equipped nor prepared to envisage the rest of mankind as anything but secondary, marginal and essentially problematic" (van Nieuwenhuijze, 1983:24).

How should we handle these conflicts of cultures? Do cultures have rights? When UNESCO talks of "absolute respect for" and "the equal dignity of all cultures", should one read this as meaning "equal worth in all respects and unconditionally", or as a diplomatic peace-treaty, or as "deemed equal in worth unless proved otherwise in certain respects"? The universalist view is summarized by Prince Claus of the Netherlands: "If we support Amnesty International...or War on Want['s work worldwide] ...we [Europeans] are actually supporting the view that some human values and the rights flowing from them are universal... there are values which we claim to be universal and by which we do judge cultures. Indeed not to do so would be to deny the humanity of the members of the societies in question" (1985:18-19). ${ }^{\text {ix }}$ In later sections we examine how such a view still can and must accomodate much local variation.

A universalist stance that legitimates cross-cultural criticism implies scope for criticism also from South to North. When documents like "A World of Difference" (BuZa, 1991) talk of "culture as a basis for sustainable development", they mean others' cultures; but what of their own culture? It becomes part of the agenda for critical examination. Second to none is the issue of how to strengthen the cultural basis in the North for sustainable development worldwide. 
A contrary position to universalism holds that the values of each culture cannot be questioned. This rests weakly if it claims to derive a universal ethical injunction -- that we should accept each culture's values -- from an assertion of the absence of universal (human) values. We remarked earlier that, in addition, this relativism is sometimes not consistently followed, and can be used to legitimate domination by the strong. Sections 3 and 4 below will consider other objections: that certain basic needs and rights take priority over local values. Here we probe weaknesses in the empirical base for relativism: in general 'the' values of 'a' culture are far from fully clear, consistent, or internally accepted. As Seyla Benhabib puts it (1995:240): 'the philosophical defences of cultural relativism, more often than not, suffer from a poor sociology'.

Too often we meet the 'when-in-Rome' fallacy: the assumption that all the members of a society or community think, feel, and behave alike, so that there are few problems about whose views, practices and interests are "the" local ones. This is usually false, especially in the late 20th century. For instance, Marty Chen stresses that:

The [fiercely disputed] demand [in parts of South Asia] that women be allowed to abandon seclusion and seek gainful employment outside the home should not be seen as an outside challenge to local culture and tradition but as a local response to changes in local culture and tradition. (Chen, 1995:55) Similarly, when Verhelst (1990) has a range of protagonists from India, one of the most resilient and adaptive culture-areas, speak for themselves, he discovers the great internal variety and disagreements within "Indian culture". He has a "flabbergasting" learning experience with forms of spirituality that feel indifferent to worldly justice or welfare (p.126); and encounters varied local criticisms of Vedanta gurus, official Gandhians, Aurobindo's followers, and more. ${ }^{\mathrm{xi}}$

For thinking about cultural plurality in a society, McGregor (1990) adds the image of a matrix of identities. A society contains "a range of overlapping possible cultural identities", not simply "a" culture (p.14). In his matrix, rows represent socio-economic classes and columns indicate identities in other dimensions -- ethnic, religious, regional, gender, ideological, urban/rural. (So one column, in McGregor's Bangladesh case, might be tribal Christian hill-tract market-town male secessionist!) Hegemonic groups often propagate the myth of "a" single culture. Still, there will generally be some shared, integrating elements internalized in nearly all, or at least most, identities in the matrix. McGregor thus refers to a society's (shared) culture as "an overarching code or rules and resources beyond those embodied in particular institutions, organisations and ideologies ...[which] provides the rules and guidelines for the integration of often competing and contradictory components of the social system" and for the mediation of their conflicts (1990:15). The questions remain: how far do the shared elements extend? and who benefit more from the particular code or rules? Verhelst remarks for instance how the neo-Buddhist 'Sarvodaya shramadana' movement in Sri Lanka mobilizes the labour of the poorer for the benefit of the richer.

A second danger, related to when-in-Rome-ism, is to mummify culture and not see it as fluid, ambiguous, and evolving; even if the time-scales are sometimes decades and generations rather than months or years. While differences do exist between cultures in the orientation to change versus stability, Simson (1985) claims that in reality almost anything can be added to a culture, if done via legitimizing channels. 
Kloos (1985) suggested a more complex model: (i) individuals' choices and behaviour occur within (ii) a framework of inherited conditions and ideas; beliefs and values at this second level are subject to considerable change, sometimes rapid, but this is within constraints set by (iii) deeper values or "cultural principles"/"cultural identity", which evolve more slowly. Goulet's (1971) model is similar.

Western self-definition involved defining "the Other", and as part of this, understating the role of reasoned debate in other cultures. Nussbaum \& Sen (1987) show how, for example, conventional pictures of traditional Indian culture seriously underemphasized rationalist components and schools. This applies even for the pictures of Indian religions and philosophy (where the greatest individual figure was the severely rational Gautama Buddha). As van Nieuwenhuijze, van den Hoek, Walzer and others note, the plurality of traditions and schools within a culture-area, its range of cultural resources -- including its ambiguities and tensions, its own rationalist traditions, its influences from other societies, its elements of alienation -- provide possibilities for internal critical reassessments, updating and growth. Review from within a culture itself permits a local awareness and sensitivity, and an argumentation that is more locally meaningful and acceptable. It draws on resources in the culture, to criticize and amend other aspects, in light of new (or resurfaced or reconsidered) experience, ideas, knowledge and comparisons, and new conditions and opportunities, including new awareness of possibilities - for example about the position of women. Ironically, some supposed post-modernists have lapsed into essentialism by assuming total definition, closure, and non-overlap of cultures.

Verhelst looks at projects to help cultures adapt and grow rather than be mummified. His book's final statement reads: "For each people or local community, it is a question of preserving or reclaiming their liberty, and ultimately, their identity" (1990:161). Note a shift from preserving or reclaiming identity; instead liberty has to be gained and sustained, and through it identity may be re-made, re-created. ${ }^{\text {xi }}$ Culture's value would lie in its free and rational construction and evolution, rather than just its preservation or restoration.

Liberty can clash with inherited culture and identity; we look at this in Section 4. And social heterogeneity and conflicting interests and perceptions mean that the limits of acceptable evolution in a local culture are in dispute and under negotiation. Chen recorded how the powerful in a Bangladesh village appeared to interpret the norms of purdah to fit their own convenience.

"What is necessary for their wives to do is sanctioned as purdah. For example, if women from rich households need to go to the town to appear in court, even to remain in town for a few days, this is sanctioned as within the norms of purdah. When women from a BRAC-organized group want to go to town to attend a workshop or meeting, even for a single day, their action is condemned as bepurdah [outside the norms of purdah]" (BRAC staff, cited by Chen, 1995:51).

So, while cultures do contain ethics, these leave large areas for ethical and other discussion. The ethics are: incomplete, ambiguous, inconsistent, plural; in dispute; required to grow and adjust in the face of qualitatively new conditions and cases; and open to criticism, for example concerning the relations between classes and genders. One can observe this in any society. Local culture serves then as one basis in 
decision, but cannot serve as an oracle.

The above fallacies in viewing cultures -- "when-in-Rome" and "when-in-the-museum" -- reflect "the dangers of a totalizing concept [applied] by the West, to others - a mechanism for aggregating and stereotyping as a means of handling the unfamiliar" (Cheater, 1991:2). Culture is not some totality preserved in a museum, temple or archive, let alone one that can be controlled and modified as per the wishes of a societal development engineer. Ironically, this aggregative stereotyping can contribute to "a reactive pride in difference among those to whom it was applied" (loc.cit.).

In Section $1 \mathrm{I}$ noted that development ethics (DE) is obliged to consider cultural plurality and divergence. In Section 2 I have suggested however that while past work on "culture and development" (C\&D) provides valuable materials it has often been held back by conceptual difficulties and over-idealization. It often fails to face the questions of whose culture, whose values, and whose benefits and disbenefits? DE work is thus a necessary complement to C\&D concerns. Section 3 now considers newer theories of basic human needs, including the capabilities approach, and how they try to accomodate, but also regulate, cultural variation.

\section{Needs and cultures}

\section{Basic needs ethics}

Basic needs ethics offers a second-stage formal theory that may be able to satisfy two "third stage" requirements: to give a ground for partial alliance between different ethics, each of which requires for its own coherence a basic needs component; and to provide an integrative programme that offers serious counter-attraction to the dominant economism. To fulfil this potential, they must meet a further requirement: allowing for extensive cultural variety. Recent work clarifies how this can be done.

The 1970s Basic Needs Approach (BNA) was widely criticized as too narrow: concerned with development for people, and insufficiently of people and by people (BuZa, 1991:40). That critique fits the more narrowly welfarist "Basic Material Needs" (BMN) work distinguished by Green (1978), Galtung (1978/9) or Hettne (1982), which was prominent in large donor agencies. It does not apply to what those authors called the "Basic Human Needs" (BHN) stream. xiii BHN work draws more fully on the content of humanist theory stretching back over centuries and millenia, and is a source of the UNDP "human development" position.

BHN theory goes well beyond material needs. One sees this already in Maslow's proposed five sets of basic needs, first stated in 1943: physiological-, safety-, affective-, esteem-, and self-actualization needs. He later, like Goulet, added "meta-needs", where the self-extension in the previous three sets moves on towards self-transcendence, in search of truth, meaning, and justification. The span beyond material needs is even more emphatic in Max-Neef's well-known framework $(1989,1991)$.

Maslow's model (1968) remains both the best known needs theory and highly controversial. Many 
cultural theorists find it particularly objectionable, if it claims that people have needs which are naturally given, not culturally moulded and mediated. Further, in Maslow's model the sets of needs arise in sequence: first we feel a need for food, and only after that for freedom, for example. Most BHN theory rejects this; passions for meaning are not restricted to the rich. The claim that needs seen as more "cultural" are postponed until after material needs (implicitly non- or less cultural) are met, also unwisely treats culture as supplementary, not central and pervasive. It reminds us that the needs analyses of some psychologists, philosophers, social planners and economists must be complemented by the perspectives of anthropology, history, literature, art and politics.

We should distinguish the following modes of "needs" theory (Gasper, 1996). First, there are theories for explaining wants and behaviour, which posit entities called "needs" which drive our actions. Maslow's theory could be read on these lines. 'Basic needs" here may mean those felt before any others, or more fundamental or general urges/forces that are actualized differently in different situations as particular needs and desires. Such theories have been superseded in most of psychology, as too crude to adequately capture human behaviours which are both intelligent and socially embedded. For example, the anthropologist Mary Douglas attacks needs-discourse that suggests the forces behind global climate change are in effect givens; Douglas and her associates from across a range of disciplines use instead her "Cultural Theory". xiv

A second mode consists of analyses to identify prerequisites for various types of capacity or functioning, e.g. the requirements of physical health. Maslow's contributions might better be read as one such attempt. (See also e.g. Argylle, 1987, and Scitovsky, 1992.) 'Basic needs' here can mean survival needs, or more generally prerequisite needs, those which must be satisfied in order to do other things.

Thirdly, ethical "needs" theories present arguments about which prerequisites have priority status, in other words constitute claims that the relevant political community should ensure are met. This is the field of Doyal \& Gough, Sen, Nussbaum, and others, and is what most concerns us here. "Basic needs" then could mean the requisites for fundamentally valued outcomes (we will give examples shortly), or the highest priority needs, or needs that a government or society must (i.e. is morally obliged to) try to ensure are satisfied. This third mode, on ethics, has little direct connection with the first mode, explaining behaviour, though both have connections to the second, identifying requisites. Psychological and cultural-theoretical critiques of needs theories concern the first mode rather than the ethical theories of need.

Basic needs ethics can help us understand unity-in-variety, by distinguishing levels of greater and lesser generality. In positive analysis, we noted how Kloos and Goulet distinguish levels of values, to understand continuity-in-change within a culture; positive needs theory tries to go further, to analyse variety across cultures, seeking generalizations about deeper source needs underlying the variety of concrete cultural features and behaviours. Whatever the strengths or weaknesses of such positive theories, distinguishing between levels helps in needs ethics; and multi-level understanding can reduce insistence that given lower-level features are sacrosanct and must be preserved.

Sen's capabilities approach fruitfully distinguishes a sequence of concepts: income - commodities - 
commodity characteristics - personal capabilities - personal functionings - well-being. Extending Sen's work, Doyal \& Gough (1991) suggest the following ethical and policy hierarchy. ${ }^{\mathrm{xv}}$

1) A level of universal or fundamental human interests, concerning certain sets of 'functionings'. Doyal and Gough define fundamental interests as "avoidance of serious harm", or as basic participation as a member of one's society. A grander specification sometimes used is "human liberation"; and beyond that, "human flourishing".

2) A level of "basic needs" required for the universal goal(s); this corresponds to Sen's "capabilities" level. Basic needs are posited by Doyal \& Gough as health (physical and mental) and autonomy. Autonomy in action is required for social participation; autonomy also in values and critical capacity corresponds to an ideal of liberation.

3) "Intermediate needs", i.e. certain sets of "characteristics" (e.g. shelter) necessary for fulfilment of level 2's basic needs/ capabilities. For basic participation the intermediate needs are specified as:- nutritional food and clean water; protective housing; a non-hazardous work environment and physical environment; appropriate health care and education; security in childhood; significant primary relationships; physical and economic security; safe child-bearing and birth control. This level matches most lists of "basic needs" in development policy.

4) Specific satisfier commodities (inputs) to fulfil the intermediate needs; these will vary according to culture, context, and the persons concerned.

5) Societal "preconditions" for the provision and use of the required satisfiers. ${ }^{\text {xvi }}$

Even with a common specification of fundamental interests, the exact content of levels (3), (4) and (5) is thoroughly socially and culturally relative, but within a shared framework. Nussbaum (1995b) speaks of 'local specification' in light of local conditions, and 'plural specification" in light of local traditions and tastes. We may further see culturally different specifications of fundamental interests and basic needs, i.e. at levels (1) and (2). The more modest definitions of interests, such as survival or basic ability to function in one's society, give less scope for cultural contention; we can expect more differences as the scope of definitions widens.

Much confusion arises in routine discussion because the label "needs" gets applied without qualification to any and all of these five levels (and to other things). People then argue fruitlessly about whether "needs" in general are universal or socially relative. Whether or not they use the "needs" label, many theorists now converge on a priority to promoting people's capabilities to achieve basic morally specified functionings, while in general leaving them freedom to make their own choices (though not for instance the choice of whether to be inoculated).

We see that normative needs language is not merely a way of campaigning for wants. It should prioritize between wants, by asking what are prerequisites for doing almost anything else or for matters of fundamental importance; freedom from ignorance, for example, is a prerequisite for autonomy. Autonomy itself must be defined partly in terms of how wants are formed (e.g. by informed choice) or validated or reformable, otherwise we may be unable to distinguish it from bondage or addiction. 
This type of theorizing on basic human needs contributes to better justified comparisons of well-being, for example in the Human Development Reports or Ekins \& Max-Neef (1992). Similarly, the attention to a plurality of needs understood over a plurality of levels helps us to better understand poverty (or rather poverties), as absolute in certain respects (the absence of basic capabilities) and at the same time in other respects inter-culturally and inter-personally relative (see e.g. O'Boyle, 1990).

Critics propose that needs analyses exaggerate human unities. Van Nieuwenhuijze (1983) laid a strong challenge to proponents of universal basic human needs, given the manifest variety of norms across cultures. ${ }^{\text {xii }}$ Gewirth (1994) responds that observation of cultural pluralism cannot undermine the logic of ethical principles such as discussed above; instead some existing norms will be shown to be ethically deficient. A complementary response came from Barrington Moore, who concluded that the critics exaggerate variety. He formed criteria for identifying possible moral feelings that have universal status:- (i) we can share the feeling concerned; (ii) other societies besides us and its "home" also share it; and (iii) for cases where it appears absent, one can identify plausible inhibiting mechanisms. Moore concluded that he could find no society without "some definition of arbitrary cruelty on the part of those in authority" (1978:26), including the theme of violation of reciprocity. Similarly he identified other posited universals meeting his criteria. ${ }^{\text {viii }}$ More generally, all societies seem to use pictures of legitimate needs, whether or not they use a single term like "needs" (Pole, 1961).

BHN-type analysis can meet to a significant degree the requirements for an effective counter-attractive approach to economism. It generates a serious empirical, conceptual, and policy research programme, as in the work of Braybrooke, Doyal \& Gough, Scitovsky, Sen and others, through to the "Human Development Reports" and work on social indicators. First-stage development ethics and some culture-and-development work can forget that there is nothing more practical than a good theory, and that a superior alternative is the best criticism. Thus longstanding powerful criticism of welfare uses of the GNP concept had little impact before alternative measures emerged. Alternatives require strength not only in theoretical terms; they must connect well to practically applicable methods, and, given the limits of any total theory, they must provide a working basis for alliances between a range of viewpoints. Mainstream economism has combined all these strengths: theoretical attractions, practical applications, and political adaptability. Sen's research programme of the last twenty years, to replace this standard liberal utilitarian welfare- and policy-economics by more humane and deeper alternatives, is having impact because it spans and links many concerns, including concepts, explanatory and normative theory, and policy proposals. Sen's work has lacked much cultural reference; his philosopher collaborator Nussbaum and others partly remedy this.

Finally, a policy priority to basic needs fulfilment can draw support from a wide range of philosophical, cultural, religious and political positions (Penz, 1991; Braybrooke, 1987). Basic needs ethics do not try to provide a full ordering of possible actions or states of the world. They simply seek to establish a minimum level to which all (community members) are entitled; beyond that they can hand over to other types of ethic. Further, those other ethics themselves require a basic needs ethic in order to become plausible. For example, a deserts ethic which says people should be rewarded in proportion to what they 
contribute, or a libertarian ethic which says that people are entitled to whatever they obtain through legal voluntary transactions, must respectively require that people are in a position to make contributions or to transact in an informed and capable way -- which in turn implies that they have at least a basic education and the conditions for a minimum acceptable level of physical and mental health. Basic needs ethics thus offer a vital area of potential consensus between otherwise conflicting positions.

\section{Beyond basic needs}

The low-income Indian state of Kerala is famous for its achievements (a term whose use we have defended) in meeting basic needs and for greatly reducing gender discrepancies in basic needs fulfilment. Yet its levels of female representation remain very low in national and State parliaments, in local government bodies (other than in reserved seats), and in all other leadership positions. And in 'political parties, cultural organisations, workers movements as well as in the voluntary sector, women's active participation is less than 10 per cent... as a rule, women [have been] assigned certain professions and freedom, thus far and no further' (Mathew, 1995:211-2). Dominant ideologies in Kerala place women clearly in the home. ${ }^{\mathrm{xix}}$

Kerala women present a supreme irony... Today they have achieved the two-child norm, the lowest infant mortality rate, the highest contraceptive use, a good health profile... So what is missing? Only individuality and a willing mind set. To the Kerala women... only a male umbrella spells social respectability or identity. Marriage continues to be the be-all and end-all, perpetuating the dowry evil.. (Leela Menon)

Women in Kerala wear an inner purdah... (a poet activist).

(Both quotes from Vellapally and Vellapally, 1995:188).

Does this matter? To whom, and why? Are there bounds to the amount of culture-relative variation permissible within and especially beyond basic needs ethics? What are the respective claims of tradition, individuals' choice or consent, and other considerations? Two major streams in Western philosophical ethics, the Aristotelian and the Kantian, have something to say here.

\section{Cultural traditions versus women's rights?}

Recent work by Onora O'Neill, Martha Nussbaum and associates examines the clashes between proclaimed women's rights or needs and proclaimed cultural traditions. O'Neill represents a Kantian approach; this treads a narrower path, defined by the requirements and implications of autonomous choice. She has rethought it in a late 20th century, multi-cultural context. Aristotelianism combines a richer picture of human personality and agency and associated requirements, with a degree of flexibility according to social context. Nussbaum has championed a new version in a series of eloquent papers and the recent volume 'Women, Culture, and Development'. 


\section{Martha Nussbaum's neo-Aristotelianism}

While Plato called for strict abstraction from local traditions and particularities, in order to identify universal truths, Aristotle's approach was more socially grounded. It reflected a commitment to rationality but also an understanding of people as community members, who share a heritage and some willingness to compromise in order to live together. The self is not the pre-social "economic man", but felt as a relational, social entity. Aristotelian ethics involved reasoned ordering of the various components of "the good life for man"; but full definitions of that were specific to a particular society's way of life, partly for reasons we saw above: different conditions and different traditions, especially for beyond more basic needs. Different cultures can have different well-argued orderings of goods. Such an approach to cultural evaluation offers a supplement to universalist views, useful for a plural, but interacting, evolving, world; ‘no doctrine vindicated itself in so wide a variety of contexts as did Aristotelianism: Greek, Islamic, Jewish, and Christian' (MacIntyre, 1981:111). Nussbaum and others explore its character and limits, and are trying to establish a neo-Aristotelianism with contemporary relevance (Nussbaum, 1990, 1992, 1995b). ${ }^{\mathrm{xx}}$ Not all versions view variation equally benignly.

While Nussbaum generally does not describe her theory as a needs ethic, it is subsumable within the hierarchical framework from Doyal \& Gough that we saw earlier. But it indeed goes further than a basic needs ethic, to a picture of many necessary elements of 'the good life for man'. Her "thick vague theory of the good" first identifies and defends a set of human functionings which it argues are universally considered desirable and taken as a normative definition of humanness (1995b:72-80). ${ }^{x x i}$ She then specifies `a somewhat higher threshold' of functionings, required for `a good human life' (1995b:81), such as: 'Being able to form a conception of the good and to engage in critical reflection about the planning of one's own life (1995b:84) - in other words, critical autonomy. The theory is 'thick' in covering a wide range of such requirements. It is vague "in a good sense, for... it admits of much multiple specification in accordance with varied local and personal conceptions. The idea is that it is better to be vaguely right [in identifying patterns] than precisely wrong [like the economic man model]" (Nussbaum, 1992:215; my additions). Vagueness is not vacuity.

Different versions of the picture of humanness will lead to very different prescriptions, not least on the position of women. Wallach (1992) warns too of pitfalls in transposing Aristotle's ideas to very different contexts (e.g. more democratic ones); and notes that Aristotle is currently invoked by authors with opposing views. $^{\text {xxii }}$ O'Neill adds:

..whereas many recent Anglophone Aristotelians emphasize that human flourishing is highly variable and sensitive to context, many German-speaking Aristotelians tend to think that human flourishing is far more socially determinate, indeed that it is not that different from the Thomist vision of flourishing accepted in Catholic social thought... Patriarchal social relations seem to many Christian Democratic Aristotelians the proper structure for human flourishing. (1995:144-5)

Any needs ethic which tries to cover all or most of life by extending its criterion of required 
functionings, beyond survival or minimal decency, to cover "liberation" and critical autonomy, "human flourishing" or "human fulfilment" may face similar problems. The more extended pictures of the human good, as in Aristotelianism, may lose the consensus achievable around more basic needs (Braybrooke, 1987). Wolf (1995) and Gasper (1996) discuss this danger in the work of Nussbaum and Doyal \& Gough respectively. The more extensive such an ethic becomes the more it will face potential conflicts with, for example, wants-based ethics: 'How far can the picture of good human functioning be independent of what people want, or at least independent of what under other conditions they would want?' (Glover, 1995:137). O'Neill (1995:145-6) suggests that while we can identify constraints that must be observed for any flourishing life, we cannot specify all the content of a flourishing life or the most flourishing lives.

\section{'Women, Culture, and Development'}

'Women, Culture, and Development: A Study of Human Capabilities', edited by Nussbaum and Jonathan Glover (1995), is a major new study from WIDER, the World Institute for Development Economics Research. It centres on, firstly, statements by Nussbaum of her extended version of the capabilities approach; and, secondly, case studies by Martha Chen of obstacles present in Bangladesh and India, under the name of local culture and tradition, to paid employment for women (not least widows) who want and need it in order to maintain themselves and their immediate families. The volume was intended 'to advance a more or less unified position on the question of women's functioning... that would attempt to answer some of the objections most commonly made against universalist accounts' (p.4). Together with the theoretical and comparative commentaries by a series of authors, the result is a valuable book. However, parts of the argumentation require synthesis, removal of over-individualistic assumptions and assertions, and fuller confrontation with opposed views. ${ }^{\text {xiii }}$

Glover sifts several possible justifications for differential treatment of men and women in access to paid employment or 'work necessary for their survival' (1995:121-2): for example any differences in need or desert. He concludes that none of these claims establish relevant differences, so the exclusion is unjust. Later he rejects the communitarian claim that justice is merely whatever a community accepts as such. We can extend his arguments.

As we saw earlier, the communitarian position assumes 'Roman' communities, with no major ambiguities or differences over values. This would be implausible even in a world of self-enclosed communities. In the modern world we each are typically members not just of local communities but have multiple affiliations, including quite often and increasingly as `members of the global human community' (Glover, 1995:138) created by 'world-wide reciprocal exchange, influence and interaction' (Benhabib, 1995:251). Communitarianism also requires that we accept what is locally accepted, regardless of the nature of influences on people's perceptions; it lacks the concepts of moral mistake and false consciousness. In contrast, the capabilities version of needs theory can justifiably reject people's utility as sufficient indicator of their situation, insofar as people have resigned and adapted themselves mentally to positions of disadvantage, or misused the capabilities they enjoyed. Likewise, O'Neill's Kantian approach requires that 
respect-worthy choices be those of autonomous agents, informed, uncoerced and able to reason.

Glover omits three more possible defences: fundamentalist claims that religious revelation decrees women's exclusion; that people (here, women) draw major satisfaction from fellow family- or community-members' well-being, and hence may willingly sacrifice themselves; and relatedly, ethics which do not take the individual as a unit to which justice must be done, at any rate on a priority basis, and may instead for example warn of ultimate social and moral collapse if gender segregation is not maintained and women are not confined to focus on childrearing and domestic tasks. We will leave aside claims of religious revelation; the anti-individualist claims, both in the empathy and social-ecology versions, demand further attention.

Many contributions to 'Women, Culture, and Development' simply presume the notion of justice as fairness to and between individuals. ${ }^{\text {xxiv }}$ Glover again provides some argument: 'I do not suppose that every person on earth cares about justice [as inter-individual fairness]... But I hope--and am cautiously inclined to believe--that certain moral values, including some recognizable version of justice, are to be found in the part of our common humanity that crosses cultural boundaries' (1995:139); in other words that an individual-focused sense of justice is universally predominant.

Adopting a stronger form of individualism, Nussbaum posits as a universal requirement of a good life: 'Being able to live one's own life... This means having certain guarantees of non-interference with certain choices that are especially personal and definitive of selfhood, such as choices regarding marriage, childbearing, sexual expression, speech, and employment' (1995b:85). Such a claim may jeopardize the potential agreement on other, lesser claims in needs- and capabilities-ethics. As Susan Wolf (1995) observes, the goals towards and methods by which capable individuals operate are not necessarily so individualistic. In large parts of the world it remains for example a valued and predominantly accepted norm that marriage is arranged by one's family. ${ }^{\mathrm{xx}}$

The social ecology claim--that societies' fine and complex balance and coherence will be jeopardized by changes in gender rights and roles--is dismissed by Nussbaum (1995b:100-2), citing Plato's perception that male and female hunting dogs have exactly the same needs and potentials, other than brief 'maternity leaves'. A difference from dogs is the extraordinary duration and attention required in nurturing human offspring. Why should women bear the brunt of that? Wolf and Glover both observe that while present biological sciences establish no such rationale, nor can they preempt the nature of future findings. At the end of his contribution, Sen too notes this social ecology claim--efficiency with gender inequality and collapse without it--more cautiously than Nussbaum and observes: 'That line of argument has to be critically scrutinized and challenged... To some extent such an analysis can draw on what has already been achieved in other countries' (1995:270). Yet doubters will ask to wait another few generations to draw conclusions on impact. Wolf suggests instead, not insisting before the fact, that there will be one norm for men and women alike, but rather... ensuring that women as well as men participate in the task of [normative] theory construction' (1995:113). This leads us towards an approach exemplified by among others Onora O'Neill, which is more procedural and perhaps less ambitious than Nussbaum's. 


\section{Onora O'Neill's Kantian liberalism}

Dower $(1983,1992)$ suggests that Kantian-style principles of the value of every human being and of their rational and free agency are shared across many philosophies and religions. O'Neill's approach is on such lines. Her work $(1988,1991)$ seeks to set some shared requirements, beyond which cultures may differ. It argues that seeking to build agreements about what is just requires abstraction without idealization, and context-sensitivity without pure relativism. Justice will be blind to irrelevant differences: it should abstract from many features of particular cases. What is irrelevant depends on the case, but would nearly always include e.g. skin colour or race; also frequently irrelevant are sex or ability. But justice should not be blind to relevant differences (which again depend on the case): it must avoid idealization of the actors concerned, implicit reference or bias towards certain types of individuals, e.g. men, the well-placed or the economically independent, the healthy, or the super-intelligent. Idealization means that certain individuals are implicitly privileged in the analysis; their position is taken as normal. Instead justice should be appropriately context-sensitive and make allowance for relevant differences.

Context-sensitivity should not turn into communitarian relativism, where too many particular local features, conventions and traditions, including prejudices and unjustified discriminations, are treated as defining relevant differences. This insulates each context or society from criticism, and re-endorses their prevailing powerholders. It in effect avoids questions of justice, by building acceptance of all local norms and cultural ideals into the very principles of justice; yet those norms (which could include bribery, foot-binding, bonded labour, a sex industry that preys on the weak, or the "traditional" carrying of weapons of intimidation) are defined mainly by the locally dominant powers, even if accepted by the dominated (e.g. women). We should abstract from acceptance by the dominated, if they are ill-informed, indoctrinated, powerless and subdued. Relativism abstracts too little; it abdicates from reasoning.

O'Neill suggests that most existing views on justice suffer either from relativism, like defences of patriarchy which argue purely in terms of local cultural traditions, or from idealization, like most Western approaches, that use a general format which is implicitly biased to men.

A table here will simplify but may help:-

\begin{tabular}{|c|c|c|}
\hline $\begin{array}{l}\text { AN OVERVIEW } \\
\text { OF O'NEILL'S REQUIREMENTS } \\
\text { FOR ANY CONCEPTUALIZATION OF } \\
\text { JUSTICE }\end{array}$ & $\begin{array}{l}\text { Are the relevant } \\
\text { taken into } \\
\text { YES (appropriately } \\
\text { context sensitive) }\end{array}$ & $\begin{array}{l}\text { differences } \\
\text { account? } \\
\text { NO (idealization) }\end{array}$ \\
\hline $\begin{array}{l}\text { Are } \\
\text { irrelevant NO (e.g. relativism) }\end{array}$ & $\begin{array}{l}\text { E.g. milder } \\
\text { patriarchy }\end{array}$ & $\begin{array}{l}\text { E.g. stronger } \\
\text { patriarchy }\end{array}$ \\
\hline $\begin{array}{lc}\text { differences } & \text { YES (appropriate } \\
\text { ignored? } & \text { abstraction) }\end{array}$ & $\begin{array}{l}\text { The desirable } \\
\text { combination }\end{array}$ & E.g. Rawls \\
\hline
\end{tabular}

Consider two claims that Rawls's Western liberal conception of justice -- a contract between citizens 
who while contracting do not know their social identity -- involves idealization. First, feminists diagnosed a bias against women (and children): for in Rawls's theory the contracting parties are heads of household and intra-household division is not deemed an aspect of social justice. Rawls's is then either only a theory of justice amongst household heads (who are predominantly male) or it assumes (falsely) that household heads almost invariably act equitably. Having criticized Rawls for ignoring relevant differences between men and women, feminists like Okin $(1989,1994)$ modify his theory to include gender roles within the ambit of rules of justice. $^{\text {xxvi }}$ Second, communitarians argue that the approach assumes actors who accept Western liberal individualism. Rawls makes this point himself and does not claim universal scope for his theory; though some argue he is wrong here.

O'Neill aims to specify universal requirements of (human) justice that avoid both relativism and idealization. She remarks that we should make realistic universal assumptions about people, and avoid non-universal assumptions. This of course leaves much space for argument; some theories take up the challenge (Section 3 above). More specifically she proposes the Kantian `requirement of acting only on principles that can be acted on by all' (O'Neill, 1995:147), i.e. any rules of justice for a particular context must be such that they could reasonably be accepted by all those involved; which means they are or would be accepted when discussed in conditions of no deceit, no fear of victimization, and ability by all to reject or renegotiate. It is not sufficient that they are accepted, for that may be in conditions of unjust domination. ${ }^{\text {xxvii }}$

Two implications of these more specific requirements could be that cultures/groups do not have rights that outweigh the rights of individuals to choose under non-coercive conditions their own practices that respect other people's similar rights; and that any group member has the right of exit. Kukathas (1992a) rejects proposed group-level rights, because groups are mutable, vary with time and context, and are not culturally uniform or homogenous in situation; and further because such rights would tend to freeze the existing patterns in and between groups. His grounds match our earlier criticisms of seeing cultures as fixed (the in-the-museum syndrome), homogeneous (the when-in-Rome fallacy) or with clearly defined bounds. He warns that group-level rights would benefit elites, who would hold the authority implied over other group members. ${ }^{\text {xxviii }}$

\section{An assessment of $O^{\prime}$ Neill}

How far is O'Neill's analysis still premised on a conception of people as individual choosers? Do people want so much choice? How far do people see themselves as separate from others, and will the analysis apply to more group- and role-oriented self-conceptions? O'Neill's account of "justice requires that institutions... allow [in a real sense] those on the receiving end, even if frail and dependent, to refuse or renegotiate any variable aspects of the roles and tasks assigned to them" (1991:455; my addition). This is very demanding. We do not apply it to children. O'Neill would reply that principles that are shared in a meaningful sense must be ones that people reasonably could and do accept, which in turn implies non-coercion, non-deception, and ability to have said no. Verma (1995:440) emphasises that this requirement of autonomous choice by individuals need not entail an atomistic self-focused individualism. 
People will sometimes disagree over how to interpret O'Neill's requirements; but the same applies to any set of principles. We remain partly unclear as to what "could" be accepted under fair conditions of discussion, and as to what exactly the latter are. She herself notes that capacities to act and negotiate are inevitably constrained by lack of abilities and by commitments to others (not least a mother's loyalty to her children). Abilities themselves are constrained by our genes and our psychic moulding from conception onwards, most of which is barely variable later.

O'Neill does not claim that her requirements will determine "the" rules of justice for particular cases, only that they set limits, within which various patterns are acceptable. And they concern only consent to rules and roles, which is a weaker and more realistic requirement than active choice.

I will suggest one interpretation of her requirements for acceptable consent (AC) through examining some cases where women accept subordinate roles. Case 1: they have no real alternative; so their acceptance does not satisfy AC requirements. Case 2: they have real alternatives, but without adequate education or sufficient awareness and information about the alternatives; this too fails to meet the requirements. $^{\text {xxix }}$ Case 3: they have real alternatives, thorough awareness, and no cultural and psychic moulding into accepting subordinate roles; their acceptance of subordinate roles is then fully valid in terms of AC principles even if unexpected. Case 3 could have as variants: (i) the women have never been moulded into any roles -- but that is absurd; or (ii) they have been de-moulded, by education and reflection, but accept one or more argument given for their subordinate role ${ }^{\mathrm{xxx}}$-- this is not absurd, but still of questionable realism for most women.

More prevalent may be Case 4: the women have real alternatives and reasonable awareness of them, but are culturally and psychically moulded into accepting, and perhaps relishing, (mainly) subordinate roles. The reports cited earlier from Kerala might describe such a case for a majority of women. The AC rules do not object to the acceptance, only require that women continually have the alternatives and (access to) a good awareness of them -- even if these two conditions go against the local culture. If such an awareness generates dissatisfaction by women with their culturally given roles, then it is no longer our Case 4, and AC rules would imply that the roles are not just. It is quite possible that earlier acceptance will eventually decline. ${ }^{\mathrm{xxxi}}$

In the key fourth case, one possible conflict is between (a) local culture and (b) women's posited rights to make informed and uncoerced choices; the other is between accepting (b), women's informed choices and consent, and (c) an ultra-rationalist or ultra-feminist wish that the women could make choices without any cultural moulding. Position (c) risks incoherence, since choice without values makes little sense; but the question remains of what sorts of cultural moulding are acceptable. Subject to qualifications concerning basic needs and rights, I support the middle position (b), accepting women's informed and uncoerced choices and consent, without considering this position either perfect or always clear. Basic rights include the requirements of autonomy of agency, not least the capacity and confidence to decide and act. Position (b) includes a requirement that no culture should prevent access to information; which goes some way towards also allowing a critical autonomy -- the ability to make a reasoned choice of values -- but certainly does not 
assume that a reasoned choice can only occur after full withdrawal from a culture, nor that there is only one reasonable choice.

Next, what is "proper awareness" of alternatives? Is information on their implications enough ? Unless one has tried out the alternatives, information may not remove feelings of habit, uncertainty and fear of the unfamiliar. But one can hardly insist that people try out alternatives before they give consent. The issue rather is: can they later withdraw consent and switch to an alternative ? O'Neill would require that they can; for example when they receive updated information, say on the experience of others who have adopted the alternative.

Her requirements do not fix what will be the answers by particular women in particular societies. The point is to ask the questions and see the answers. If rules about roles cannot be applied only to some people and not to all, one would have to ask in addition: a) what proportion of women do accept (under acceptable conditions) a certain assigned role?; and b) what is the maximum tolerable figure for the proportion of women who reject it? (1\%? 5\%? 20\%? 49.99\%?) For purists the maximum tolerable is zero; but an ideal of the renegotiability of everything by anyone, even a single person, may lack plausibility.

O'Neill has not tried to give a total and universal theory of justice, but instead proposed some constraints on what is acceptable cultural variation. The room for debate in defining and interpreting those constraints underlines how hard--or, given the considerable malleability of human nature, perhaps impossible--it might be to establish as universally valid a set of principles of justice with very extensive substantive content.

\section{Conclusion - cultural critiques and ethical alliances}

I have proposed that "first-stage" development ethics (DE)'s criticisms of economism, and reference to multiple different appealing principles, such as autonomy, rights, or freedoms, are not enough. We require "second-stage" systematic theorizing, to refine and relate different principles and build coherent alternatives; and "third-stage" transference back to the worlds of practice and compromise. In doing this DE must in particular face the challenge of cultural plurality and divergence. Unfortunately work on "culture and development" (C\&D) provides important materials but has often been hindered by conceptual limitations, over the meaning of 'culture' and when faced with the ambiguities, variety, conflict and change within societies. An injunction like 'When in Rome, do as the Romans reportedly used to' has little contemporary practical or moral force.

Third-stage work includes seeking areas of agreement between different viewpoints; whether agreement on certain principles or agreement on some practical conclusions despite differences on principles. The U.N. Declarations on Human Rights for example largely avoid attempting agreement on theory and methodology, and focus on some relatively practical matters; but what then gives them plausibility? I have argued that basic needs ethics offer a worthwhile area for a partial consensus between 
many views; and that the modified Kantian approach of O'Neill may add a further zone of consensus amongst at least some views.

Basic needs ethics may satisfy several "third stage" requirements: i) sustaining an alliance between several perspectives, each of which requires for its own coherence a basic needs component, ii) providing an integrative research programme that offers serious counter-attraction to the dominant economism, and iii) accomodating considerable cultural variation. While needs discourse is sometimes dismissed as explanatorily primitive and blind to cultural diversity, recent restatements distinguish: (a) between different modes of needs theorizing, clarifying that needs ethics have no fundamental linkage to needs psychologies; and (b) between different levels (from functionings down to commodities), in a universalistic framework that yet provides great scope for legitimate cultural and contextual variation -- both in fulfilling general types of need and in life beyond basic needs. It makes clear that we should never reduce "cultural needs" to a separate category or one supposedly felt only by the well-off.

When considering possible bounds to the culture-relative variation in and beyond fulfilment of basic needs, the work of Onora O'Neill deserves attention. Her theory of justice in a cross-cultural context asks what is acceptable cultural variation and what are universal principles, with special reference to the position of women. In her view, seeking to build agreements about what is just requires abstraction without idealization, and context-sensitivity without pure relativism. In situations of conflicts between (a) local norms (insofar as these are clear) of gender hierarchy, (b) women's informed and uncoerced but culturally moulded consent to subordinate roles, and (c) an ideal (for some) of choices made without any cultural moulding, an approach derived from her may lead to acceptance of (b), women's informed consent, though without considering this stance perfect or always clear, and subject to qualifications concerning basic needs and rights.

Nussbaum presents as an example of agreement on both principles and practical conclusions, the convergence on 'a historically sensitive universalism' (1995a:8) by the philosophers (including O'Neill) in the 'Women, Culture, and Development' volume, who come from a range of Western traditions -Aristotelian, utilitarian, Kantian, pragmatist, and Habermas's dialogical approach -- and Southern countries; and their considerable consensus about specific issues of women's rights in developing countries. This is indeed significant, but since Nussbaum selected participants for the conference and explicitly intended the volume as a unified statement, it remains a limited test.

She sees the main area of continuing disagreement within this circle of thinkers as between those (like herself) who propound substantive yet universal ethical requirements and those (like O'Neill and Benhabib) who emphasize instead a just decision-making procedure; but adds how close the two can come in practice. Thus any just procedure has many substantive prerequisites -- such as, in most cases, literacy of all participants -- and the work on Basic Human Needs and capabilities stresses exactly these. And the gap further narrows when we look to the Doyal-Gough version of basic needs theory, which identifies ('intermediate') needs as the prerequisites for autonomy, and goes on to link needs theory and the post-Kantian dialogical ethic of Habermas. 


\section{NOTES}

i. Mainstream economistic development ideas and strategies typically have utilitarian (in the narrower technical sense) or libertarian ethics (see Lal, 1976; Gasper, 1986).

ii. E.g. "Is autonomy not the goal?" (BuZa, 1991:38); for women, "basic needs [should] become basic rights" (p.204); and "the overriding goal of Dutch development policy [is] to reduce poverty on a lasting basis" (p.292). Statements of priority to both individual autonomy and poverty reduction might be integrated (but modified) via for example Sen's normative theory; both then need integration with the claims of culture etc.

iii. The term "generation" was used by David Korten (1990) for NGOs, to connote sequence, chronologically but also in terms of intellectual maturation I referred to "three generations" of development ethics in early drafts of this paper, with the emphasis on intellectual maturation rather than just passage of time. The terminology was adopted by Carmen (1994), but with a presumption of intellectual maturation over time. Thus in his terms Max-Neef's work (1991) on Fundamental Human Needs is "third-generation"; in my terms it is more "first stage", for despite rich insights and some orientation to practical uses it remains imprecise in important respects and has not built on or engaged in close "second stage" analysis. I here use the term "stage", because "generation" has too strong a chronological connotation, and "level" is too hierarchical; whereas I foresee a continuing role for work at each stage. 'Stages' are found in parallel as well as in sequence. Ethical reflection on culture-and-development issues may have increased with time, but it naturally spans all three stages of DE.

iv. See e.g. the identity statement of the International Development Ethics Association in the early 1990s.

$\mathrm{v}$. This is critical autonomy, the ability to choose values, not only to act capably with reference to given values.

vi. See also the interesting commentaries, especially by Apel and Hussein, in a special issue of UNESCO Courier, Double Issue on "Universality: A European Vision?", July/August 1992.

vii. In position $(\mathrm{C})$ too, ethical as well as cause-effect claims are implied in saying that culture is a need, in the sense of a justified priority. $\mathrm{X}$ is deemed such a need if 1 . it is required for achieving $\mathrm{Y}$, and 2 . $\mathrm{Y}$ is accepted as a high priority / important aspect of humanity.

viii. Paradoxically, in origin the term "culture" (as e.g. in "agriculture") concerns types of effective use (Williams, 1983). Williams traces its later evolution in reaction to economism.

ix. See Agnes Heller (1984) for a subtler analysis of why total cultural relativism in ethics contradicts a contemporary, cosmopolitan, sense of justice.

$\mathrm{x}$. If the sociology behind relativism is thin, what of that behind universalism? Benhabib claims that ethical universalism, 'the moral imperative to treat others with universal respect and according to egalitarian reciprocity....only make[s] sense against the background of the hermeneutic horizon of modernity; but...modernity, although.....first assembled in the West, is a world-wide process and phenomenon....a common human project and not just a Western one.... fundamental aspects of the culture of the West have long become a global reality' (1995:253-4). Globalization has mixed impacts, though; often it provides both the incentive and the means for intensified enforcement of some interpretation of group 'traditions'.

xi. Yet when he comes to Africa, Verhelst indulges in sweeping remarks about "the African": pp.26-7, 39; and, odd even when written: "Black Africa seems incapable of mass mobilization", p.43, likewise pp.44, 158.

xii. The UNESCO Second Medium Term Plan for 1984-89 recommended, first, an 'infant industry' phase of protection of cultural identities, allowing them to regain creativity for a second phase of innovation (cited in van den Hoek, 1988:41).

xiii. The distinction is lacking too in Illich's careless and outdated 1992 dictionary entry on needs.

xiv. "Cultural Theory" claims that the cultural biases in all human groups and societies can be analyzed effectively by a $2 \times 2$ matrix of cultural types, using dimensions of a) strength of commitment to a group and b) strength of behaviour regulation ("grid"). It argues that all stable societies require and contain some combination of these four different cultural biases: 1 . high-grid high-group = ascribed hierarchy; 2 . high-grid low-group $=$ atomized 
subordination; 3. low-grid low-group = individualism; 4. low-grid high-group = factionalism. See Thompson, Ellis \& Wildavsky (1990).

xv. Doyal \& Gough's book won both the Gunnar Myrdal prize and the Isaac Deutscher prize in 1992.

xvi. Relevant types of material precondition concern: i) production conditions, which affect the nature of satisfiers produced; ii) distribution arrangements, which affect to whom the satisfiers go; iii) the effectiveness of transformation of the satisfiers into satisfactions, which depends on how the satisfiers are used; iv) arrangements for material re-production (Stewart, 1985).

xvii. For van Nieuwenhuijze the key issue was whether nearly all cultures accept a notion of basic needs. "The question how universal [basic needs] really are is by and large anathema... (1)...whether needs are basic or not in any specific situation or culture area depends (a) on whether the human collectivity concerned employs a distinct socio-cultural category referred to by the word 'needs' or its equivalent [DG: why?], and (b) on whether amongst these needs some are discerned as basic as against others that are not basic, and furthermore (2)... whether basic needs are universal depends on (a) whether all or a considerable number of human collectivities - civilizations, cultures or whatever - do recognize basic needs, (b)... and identify a number of specific ones, and (c) show significant parallelism, as between one another, as regards the ones thus specified" (1983:51-2). His questions look more manageable when we distinguish (i) between levels of generality, and also (ii) between a framework for justification such as Doyal \& Gough's and particular specifications of that framework which vary according to the criteria of fundamental human interests used in its level 1.

xviii. What Moore considered are feelings in a situation of a certain type; if the type of situation is absent in a particular society then that feeling could not arise anyway.

xix. Mathew (1995) and Franke \& Chasin (1994) provide these indicators or the supporting data:-

Sex ratio (women:men)

Birth rate per woman, 1990

Infant deaths/1000 live births, 1992

Life expectancy of women, 1990 (years)

Adult literacy, 1991

Families using birth control

Women's formal employment, 1981 \& as \% of men's rate

$\begin{array}{lll}\text { Kerala } & \text { All-India } & \text { China } \\ 1040: 1000 & 929: 1000 & \\ 1.8 & 4 & 2 \\ 16.5 & 83 & 28 \text { - boys } \\ \text { (17:boys, 16:girls) } & & 33 \text { - girls } \\ 74 & 59 & 71\end{array}$

91\% (wom: $87 \%$ ) $\quad 39 \%$

$80 \% \quad 43 \%$

$13 \% \quad 14 \%$

$32 \quad 27$

Women in Kerala seats in national parliament: 1995: 10\%; 1957-95: 3\%; 1977-95: 4\%. Women in Kerala State Assembly: 1995: 5.7\%; 1957-95: 3.4\%.

xx. See also the sympathetic but probing assessment by Crocker $(1992,1995)$.

xxi. Susan Wolf corrects Nussbaum's claim that her list gives requirements for being considered human; rather it indicates `a set of needs and [priority] goals' that cannot be traded-off 'in any drastic way for the sake of other significant goals' (Wolf, 1995:108).

xxii. Wallach further warns that while "Aristotle sanctions a vast array of invidious social, racial, and sexual prejudices and displays severe analytical anc observational limitations", the very anachronism of his thought can appeal to those uneasy at "the victories of liberalism and the Enlightenment" (1992:614). Or can his disagreeable prejudices be shorn from his system without eliminating its coherence? (p.618). Wallach claims, without detailed argument, that the "system" really is a system, closed and fundamentally linked to a particular (anti-democratic) political agenda in an ancient Greek setting.

xxiii. Chen is very brief on defences used by those placing the obstacles to female employment, nor do they speak in their own words. Chen's cases are also not ethically the hardest: her women are hindered in doing what they openly wish to do. But other authors in the volume consider cases of culturally moulded acceptance.

xxiv. E.g. Sunstein explicitly defines as morally irrelevant any differences in circumstances that have `no relationship to individual entitlement or desert.. 
Sex is certainly a morally irrelevant characteristic in this sense' (1995:349; emphasis added).

xxv. Similarly, Leela Gulati records that 'In low income households [in Kerala]... the decision whether [an individual is] to migrate [to the Middle East or not is a joint household decision and not that of an individual [man or woman]... The older a wife is, the more actively she is supportive of the decision of her husband to migrate. Even mothers had worked actively for their sons' migration... Women play an active role in the decision making process by organizing networks, contributing jewelry to raise finance, and willingly supporting the family left behind' (Gulati 1995:192). Migration botl strengthens women's capabilities and increases their (and their family's) dependence on their kin network.

xxvi. The contractors in a Rawlsian "original position" would be asked to decide on the rules governing relations between men and women withou knowing whether they are or will become men or women. The focus is on informed choice but, unlike in O'Neill's approach, on a hypothetical choice where biassing information (about one's gender role) is excluded.

xxvii. Most people find it easier to live with the belief that there are acceptable reasons for their situation rather than none. Sunstein (1995) reviews considerable literature on such psychic adaptations to disadvantage, which make people's own statements insufficient as indicators of their situation.

xxviii. See Kymlicka (1992) for an opposed view, and Kukathas's reply (1992b).

xxix. Li suggests that in contemporary China 'women have not had much opportunity to be exposed to, nor allowed to, hold alternative ideas of female role. In the absence of alternative conceptions they could only react against, from an older traditional point of view, the alienated tough heroine mode idolized by the communist revolutionaries... The capability to conduct practical reasoning... is restricted by the Chinese political ideology as well as by the Confucian moral doctrines' (1995:416-7).

xxx. We have seen proffered: lesser need or desert or suitability; the authority of tradition or religion; the virtue of sacrifice for others; the risk otherwise of social collapse. Note that we are not here discussing distinct but non-subordinate roles; see Catherine Hakim (1995).

xxxi. Sen (1985) and Nussbaum (1992) cite a poll in India in which widowers had far more complaints about their health status than did widows, even though the widows' health status was worse. After some years, widows had become less reconciled to the convention that they should eat less, and a new poll found that widows expressed much more dissatisfaction than before, though their objective health status was little changed. Polls on educational status give similar results. 


\section{REFERENCES}

Aman, K., ed., 1991. Ethical Principles for Development: Needs, Capacities or Rights, Upper Montclair, NJ: Institute for Critical Thinking, Montclair State University.

Apel, K.O., 1992. The Moral Imperative. UNESCO Courier, July/August, 13-17.

Argylle, M., 1987. The Psychology of Happiness. London: Methuen.

.Beitz, C., 1979. Political Theory and International Relations. Princeton: Princeton U.P.

Benhabib, S., 1995. Cultural Complexity, Moral Interdependence, and the Global Dialogical Community. Pp.235-55 in Nussbaum \& Glover (eds.).

Berger, P., 1974. Pyramids of Sacrifice. New York: Basic Books.

Braybrooke, D., 1987. Meeting Needs. Princeton: Princeton U.P.

BuZa (Buitenlandse Zaken, Ministerie van), 1990. Een Wereld van Verschil. The Hague: Netherlands Ministry of Foreign Affairs.

----, 1991. A World of Difference. The Hague: Netherlands Ministry of Foreign Affairs / SDU Printers.

Cameron, J., 1992. Adjusting Structural Adjustment: Getting Beyond the UNICEF compromise. Pp.291-308 in P.Mosley (ed.): Development Finance and Policy Reform, London: Macmillan.

Carmen, R., 1994. Development Ethics - the rediscovery and reclamation of meaning. Development, 1994(4), 17-23.

Cheater, A., 1989. Managing Culture en route to Socialism: The Problem of Culture 'Answering Back'. Inaugural lecture, Harare: University of Zimbabwe Publications, 1991. (Also in Zambezia, 16(ii), 1989.)

Chen, M., 1995. A Matter of Survival: Women's Right to Employment in India and Bangladesh. Pp.37-57 in Nussbaum \& Glover (eds.).

Claus, Prince. Economic and Technological Progress in Relation to Cultural Development. In Netherlands UNESCO Commission, pp.18-22.

Corbridge, S., 1994. Post-Marxism and Post-Colonialism: the Needs and Rights of Distant Strangers. Pp.90-117 in D. Booth (ed.), Rethinking Social Development - theory, research \& practice, Harlow: Longman.

Crocker, D., 1991. Toward Development Ethics. World Development, 19(5), 457-83.

----, 1992. Functioning and Capability: The Foundations of Sen's and Nussbaum's Development Ethic. Political Theory, 20(4), 584-612.

----, 1995. Functioning and Capability: The Foundations of Sen's and Nussbaum's Development Ethic, Part 2. Pp.153-98 in Nussbaum and Glover (eds.), 1995.

Dower, N., 1983. World Poverty: Challenge and Response. York: Ebor.

----, 1992. The Nature and Scope of Development Ethics. Seminar paper, Dept. of Philosophy, University of Iceland, March 1992.

Doyal, L., \& Gough, I., 1991. A Theory of Need, London: Macmillan.

Ekins, P. \& Max-Neef, M., (eds.), 1992. ․ Real-Life Economics. London: Routledge.

Esteva, G., 1992. Development. Pp.6-25 in W. Sachs (ed.), 1992.

Franke, R., \& Chasin, B., 1994 (2nd edition). Kerala - Development through Radical Reform. New Delhi: Promilla \& Co.

Galtung, J., 1978/9. The New International Economic Order and the Basic Needs Approach. Alternatives, IV, 455-76.

Gasper, D., 1986. Distribution and Development Ethics. In R. Apthorpe \& A. Krahl (eds.), Development Studies: Critique and Renewal, pp.136-203. Leiden: Brill.

----, 1993. Policy Analysis and Evaluation - an agenda for research and education. Working Paper 140, ISS, The Hague.

----, 1994. Development Ethics - An Emergent Field? In R. Prendergast \& F. Stewart (eds.), Market Forces and World Development, pp.160-185. Macmillan: Basingstoke. Also as Working Paper 134, ISS, The Hague.

----, 1996. Needs and Basic Needs: a clarification of meanings, levels and streams of work. Working Paper 210, ISS, The Hague; and pp.71-101 in G. Köhler et al. (eds.), Questioning Development, Marburg: Metropolis Verlag.

Gewirth, A., 1994. Is Cultural Pluralism Relevant to Moral Knowledge? Social Philosophy and Policy, 11(1), 22-43. 
Glover, J., 1995. The Research Programme of Development Ethics. Pp.116-39 in Nussbaum \& Glover (eds.).

Goulet, D., 1971. The Cruel Choice. New York: Athenaeum.

----, 1977. The Uncertain Promise - Value Conflicts in Technology Transfer. New York: IDOC/North America Inc.

Green, R.H., 1978. Basic Human Needs, IDS Bulletin, 9(4), 7-11.

Gulati, L., 1995. Migration and Social Change in Kerala. India International Centre Quarterly, 22(2-3), 191-202.

Hakim, C., 1995. Five Feminist Myths about Women's Employment. British Journal of Sociology, September.

Heller, A., 1984. Can Cultural Patterns Be Compared? Dialectical Anthropology, 8, 269-76.

Hettne, B., 1982. Development Theory and the Third World, Stockholm: SAREC.

Hofstede, G., 1994. Cultures and Organizations. London: HarperCollins.

Hoek, A. v.d., 1988. Cultural Diversity and the Ideology of Development, University of Leiden: LIDESCO.

Hussein, M., 1992. The common ground of humanity. UNESCO Courier, July/August, 20-23.

Illich, I., 1992. Needs. In W. Sachs (ed.), 1992, pp.88-101.

Kloos, P., 1985. Culture and freedom to manouevre. In Netherlands UNESCO Commission, 64-8.

Korten, D.C., 1990. Getting to the Twenty First Century. West Hartford, CT: Kumarian Press.

Kottak, C.P., 1991. When People Don't Come First: some sociological lessons from completed projects. Pp.431-64 in Putting People First, ed. M. Cernea, 2nd edn., New York: Oxford Univ. Press.

Kukathas, C., 1992a. Are There Any Cultural Rights? Political Theory, 20(1), 105-39.

----, 1992b. Cultural Rights Again - A Rejoinder to Kymlicka. Political Theory, 20(4), 674-80.

Kymlicka, W., 1992. The Rights of Minority Cultures - Reply to Kukathas. Political Theory, 20(1), 140-46.

Lal, D., 1976. Distribution and Development. World Development, 4(9), 725-38.

Li, X., 1995. Gender Inequality in China and Cultural Relativism. Pp.407-25 in Nussbaum \& Glover (eds.).

MacGregor, A., 1990. Culture Blindness, Institutions, and the Analysis of Policy in Developing Countries. Paper to 1990 DSA conference, Glasgow.

MacIntyre, A., 1981. Against Virtue. London: Duckworth.

Maslow, A., 1968. Toward a Psychology of Being, Princeton: Van Nostrand.

Mathew, G., 1995. The Paradox of Kerala Women's Social Development and Social Leadership. India International Centre Quarterly, 22(2-3), 203-14.

.Max-Neef, M., 1989. Human-Scale Development. Special issue of Development Dialogue. Expanded as: Human-scale Development, New York/London: Apex Press, 1991.

Moore, B., Jr., 1978. Injustice. London: Macmillan.

Netherlands National Commission for UNESCO, 1985. The Cultural Dimension of Development. The Hague: Nationale Unesco Commissie.

Nieuwenhuijze, C. van, 1983. Culture and Development - the prospects of an afterthought, Occasional Paper 97, ISS, The Hague.

Nussbaum, M., 1990. Aristotelian Social Democracy. Pp.203-52 in R.B. Douglass et al (eds.), Liberalism and the Good, Routledge.

----, 1992. Human Functioning and Social Justice: In Defense of Aristotelian Essentialism. Political Theory, 20, 2, 202-246.

----, 1995a. Introduction. Pp.1-34 in Nussbaum \& Glover (eds.).

----, 1995b. Human Capabilities, Female Human Beings. Pp.61-104 in Nussbaum \& Glover (eds.).

----, \& Sen, A., 1987. Internal Criticism and Indian Rationalist Traditions. Working Paper 30, WIDER, UN University, Helsinki.

---- \& Sen, A. (eds.), 1993. The Quality of Life, Oxford: Clarendon.

---- \& Glover, J. eds. 1995. Women, Culture, and Development - a study of human capabilities. Oxford: Clarendon.

O'Boyle, E.J., 1990. Poverty: a concept that is both absolute and relative because human beings are at once individual and social. Review of Social Economy, pp.2-17.

Okin, S.M., 1989. Justice, Gender and the Family. New York: Basic Books.

----, 1994. Gender Inequality and Cultural Differences. Political Theory, 22(1), 5-24.

O'Neill, O., 1986. Faces of Hunger: An Essay on Poverty, Justice and Development. London: Allen \& 
Unwin.

----, 1988. Ethical reasoning and ideological pluralism. Ethics, 98, 705-22.

----, 1991. Justice, gender, and international boundaries. British J. of Political Science, 20, 439-59; \& in Nussbaum \& Sen (eds.), 1993.

----, 1995. Justice, capabilities, and vulnerabilities. Pp.140-52 in Nussbaum \& Glover (eds.).

Penz, P., 1991. The Priority of Basic Needs: Toward a Consensus in Development Ethics for Political Engagement. In Aman (ed.), 1991, pp.35-73.

Pole, D., 1961. Conditions of Rational Inquiry, London: Athlone.

Sachs, W., 1992. Introduction. Pp.1-5 in Sachs (ed.), 1992.

---- (ed.), 1992. The Development Dictionary, London: Zed.

Scitovsky, T., 1992. The Joyless Economy, New York: OUP. 2nd edn.

Sen, A.K., 1985. Commodities and Capabilities. Amsterdam: North Holland.

----, 1995. Gender Inequality and Theories of Justice. Pp.259-73 in Nussbaum \& Glover (eds.).

Simson, U., 1985. Development and culture. In Netherlands UNESCO Commission, 74-7.

Stewart, F., 1985. Planning to Meet Basic Needs. London: Macmillan.

Sunstein, C., 1995. Gender, Caste and Law. Pp.332-59 in Nussbaum \& Glover (eds.).

Thompson, M., Ellis, J., \& Wildavsky, A., 1990. Cultural Theory. Boulder: Westview.

UNDP, 1990 and annually, Human Development Report. New York: Oxford Univ. Press.

Vellapally, S., \& Vellapally, M., 1995. Repeal of the Travancore Christian Succession Act 1916 and its Aftermath. India International Centre Quarterly, 22(2-3), 181-90.

Verhelst, T., 1990. No Life Without Roots, London: Zed Press.

Verma, R.R., 1995. Femininity, Equality, and Personhood. Pp.433-443 in Nussbaum \& Glover (eds.).

Wallach, J.R., 1992. Contemporary Aristotelianism. Political Theory, 20(4), 613-41.

Walzer, M., 1987. Interpretation and Social Criticism. Cambridge, Mass.: Harvard Univ. Press.

Williams, R., 1983. Keywords. Fontana.

Wolf, S., 1995. Commentary on Nussbaum's Human Capabilities, Female Human Beings. Pp.104-115 in Nussbaum \& Glover (eds.). 